\title{
Surgical Treatment of Impacted Tooth Associated with a big Odontoma: Piezosurgery Approach
}

\section{Cardarelli Angelo ${ }^{1 *}$, Michele Grechi ${ }^{1}$ and Arun K Garg ${ }^{2}$}

${ }^{1}$ Specialist in Oral Surgery, Adjunct Professor, Department of Dentistry, San Raffaele University of Milan, IRCCS San Raffaele Hospital, Milan, Dean Prof. E.F. Gherlone, Italy

${ }^{2}$ Former Professor of Surgery, Division of Oral and Maxillofacial Surgery, Department of Surgery, School of Medicine, University of Miami, Florida, USA

*Corresponding Author: Cardarelli Angelo, Specialist in Oral Surgery, Adjunct

Professor, Department of Dentistry, San Raffaele University of Milan, IRCCS San

Raffaele Hospital, Milan, Dean Prof. E.F. Gherlone, Italy.
Received: March 26, 2020

Published: April 27, 2020

(C) All rights are reserved by Cardarelli

Angelo., et al.

\begin{abstract}
The aim of this study is to describe a clinical case about a young patient, 13 years old, that he has a big odontoma in the right site of the mandible associated with an impacted tooth. So, it was described a piezo surgery approach in order to obtain a conservative approach.
\end{abstract}

Keywords: Piezosurgery; Impacted Teeth; Odontoma

\section{Introduction}

The surgical treatment of included (total of partial) teeth is a most common procedure in Oral and Maxillofacial Surgery [14]. This procedure could be sample or more difficult in relation to many variables about to the element to be extracted such as localization, anatomy of the dental and the roots, depth and type of inclusion, etc. It is essential to perform a correct treatment planning to minimize the risk of post-surgical complications (pain, edema, trismus, alveolitis) and always with the lowest biological cost for the patient [5-7]. In recent years, many technological innovations are introduced in oral surgery, in particular, the use of ultrasound applied to surgery has changed some of the most frequent clinical procedures, such as the extraction of the dental elements included, introducing a new concept: piezoelectric surgery or piezosurgery [8-12].

\section{Surgical technique}

The Patient has taken an antibiotic prophylaxis with $2 \mathrm{gr}$ of amoxicillin $1 \mathrm{~h}$ before the surgery that has been done in general anesthesia then it was been done an infiltration with adrenaline at the buccinator nerve (Figure 1-4). So, it was been done A fullthickness trapezoidal flap with a vertical incision in the anterior site close the canine to avoid the emergence of alveolar nerve and a distal incision with a vestibular direction. After that it was been done an ostectomy cut with piezosurgery insert to obtain a bone window to allow the enucleation of odontoma, after the section (Figure 5-8). Then it was extracted the impacted first molar that it was in horizontal position in close contact with the emergence of alveolar nerve (Figure 9 and 10). Then the residual cavity was filled with a sponge haemostatic collagen and at the end it was been done the horizontal mattress sutures and single knots (Figure 11-16).

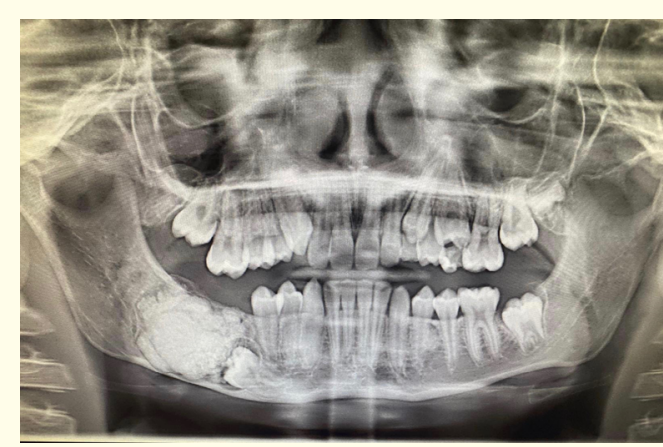

Figure 1: Initial OPT.

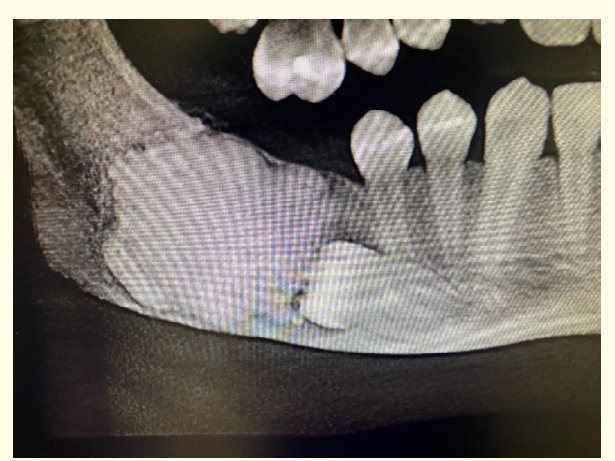

Figure 2: CBCT that shows the relationship between the odontoma and impacted tooth. 


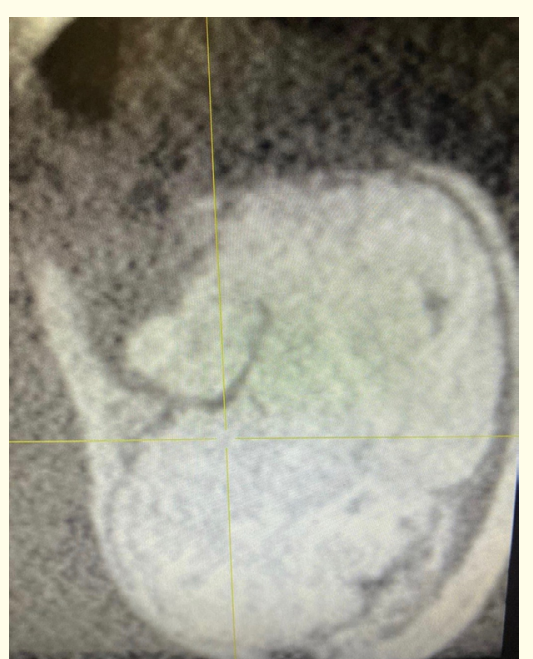

Figure 3: CBCT that shows a large odontoma.

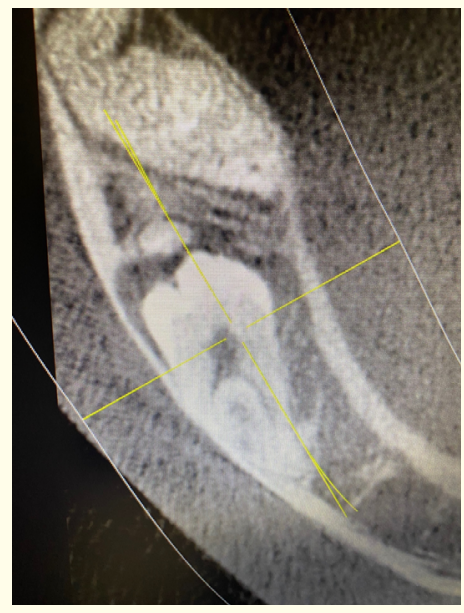

Figure 4: CBCT section that shows the impacted first molar in horizontal position.

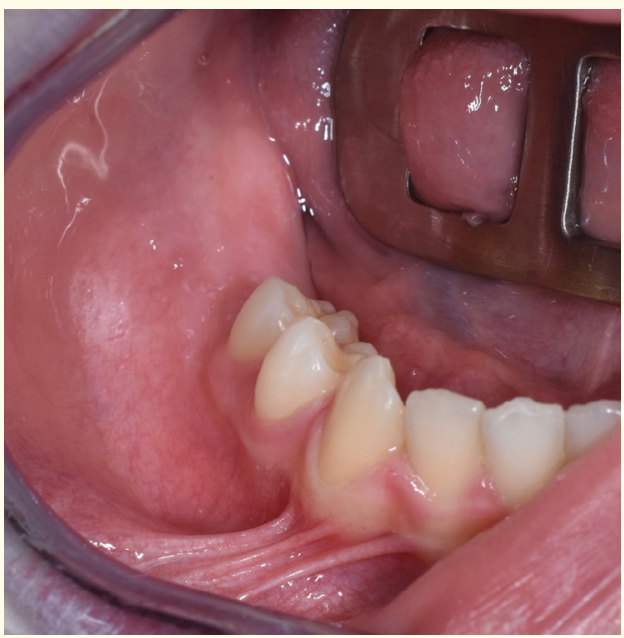

Figure 5: Initial clinical view.

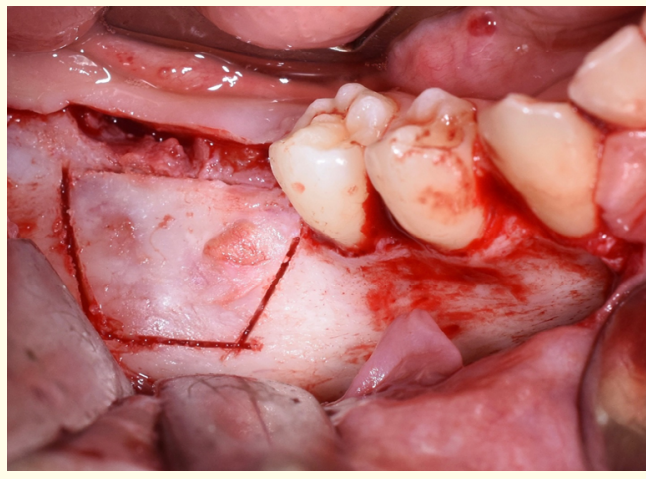

Figure 6: Ostectomy with piezosurgery.

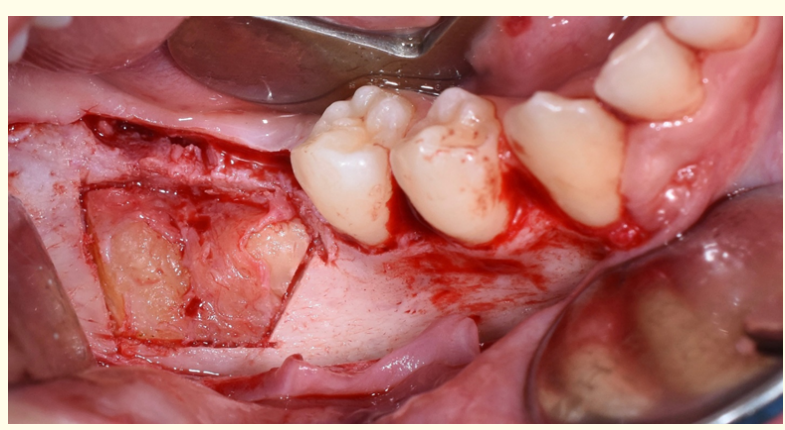

Figure 7: Surgical view of odontome after bone removal.

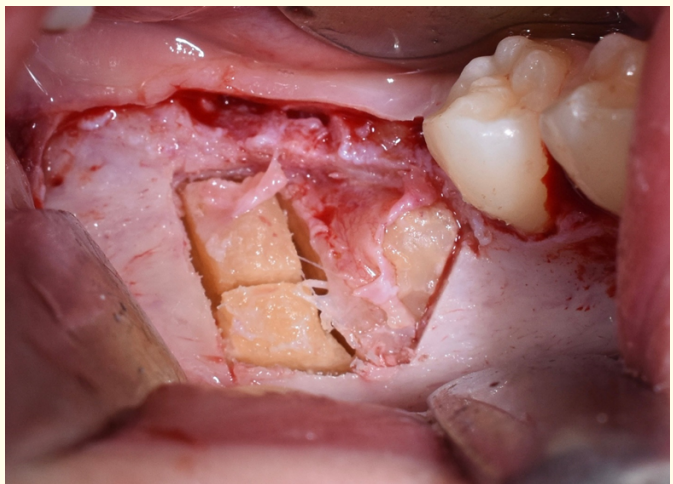

Figure 8: Section of odontoma.

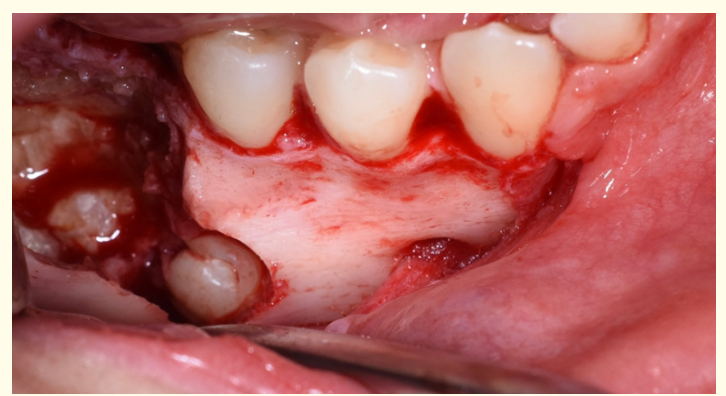

Figure 9: The crown of impacted first molar after odontoma removal. 


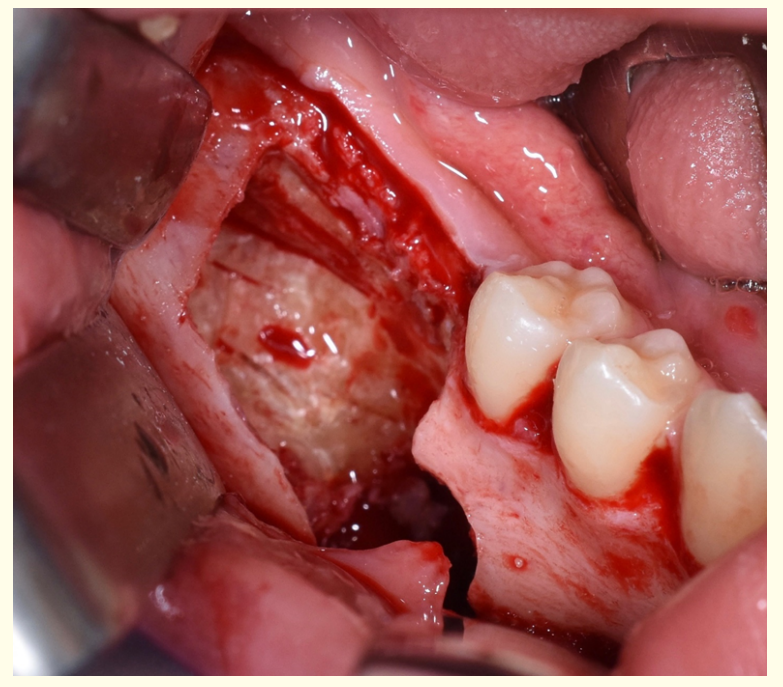

Figure 10: Residual cavity after extraction.

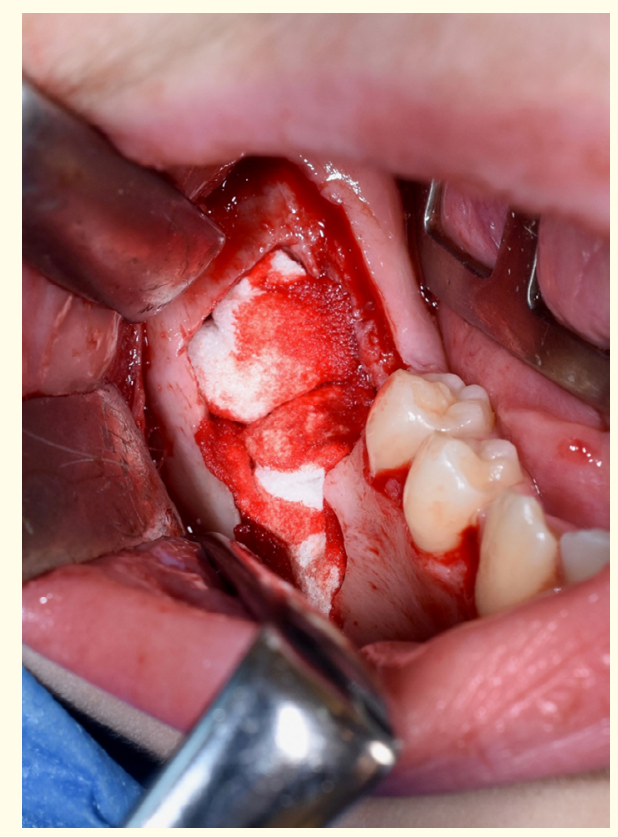

Figure 11: Cavity filled with sponge collagen.

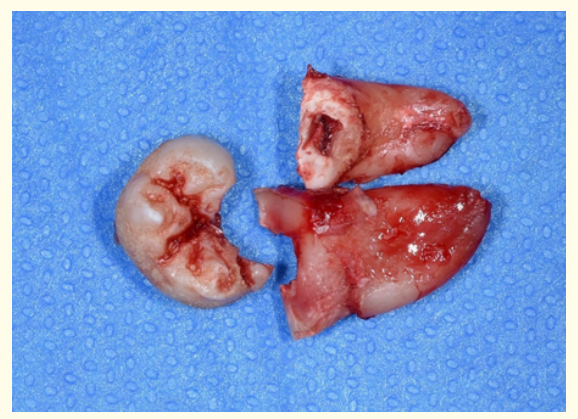

Figure 12: The tooth after extraction.

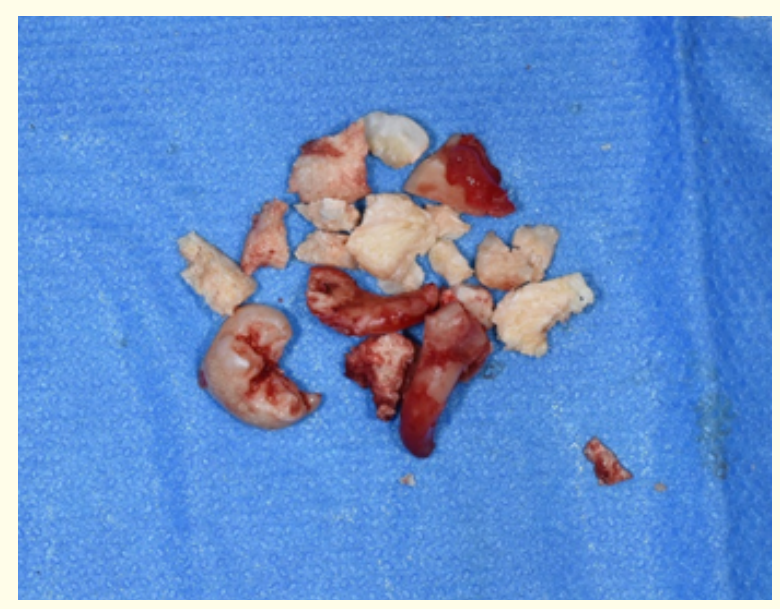

Figure 13: Odontoma removal.

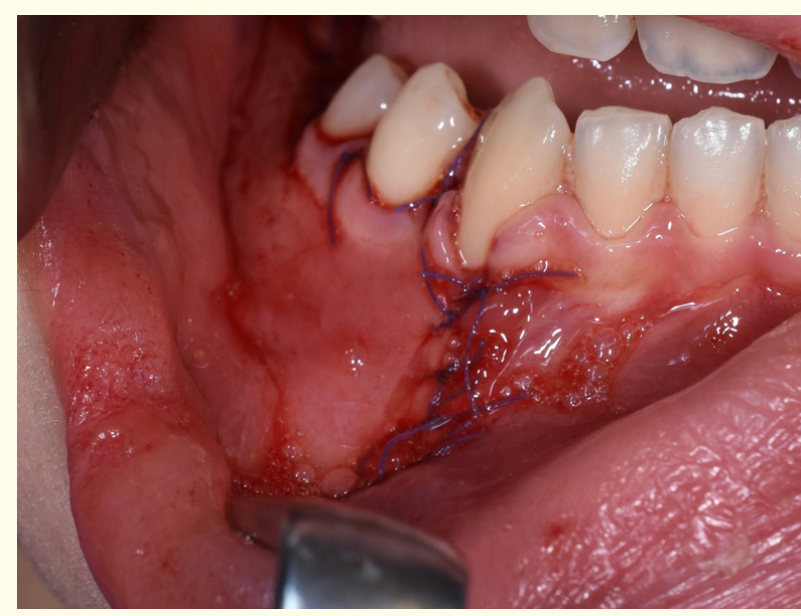

Figure 14: Sutures.

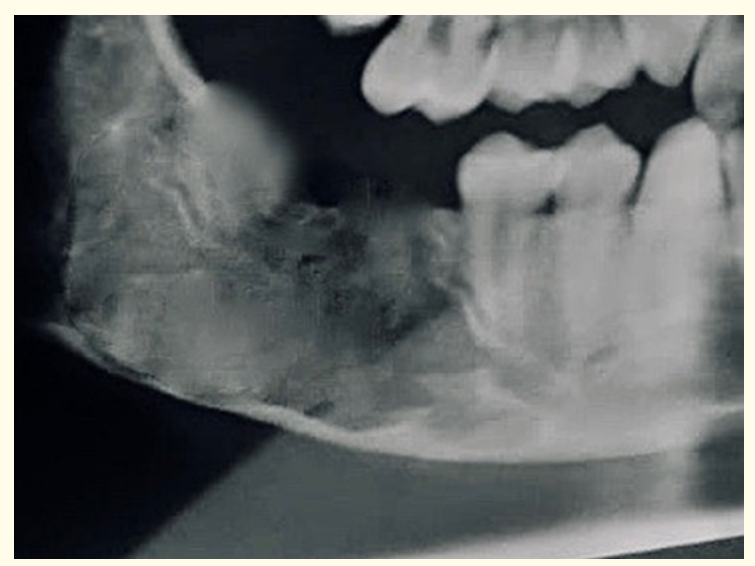

Figure 15: Post-op X-ray. 


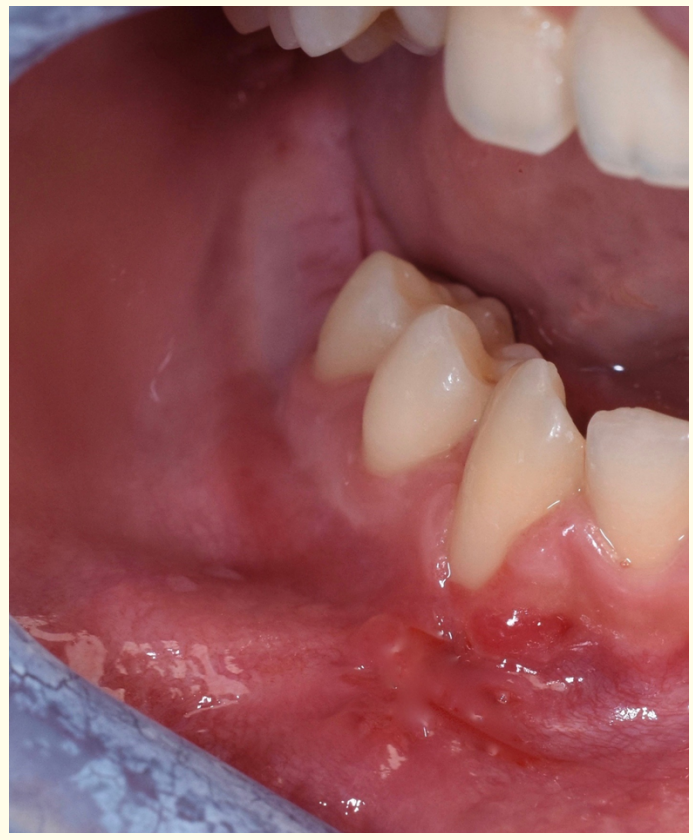

Figure 16: Healing soft tissue after two weeks.

\section{Conclusion}

In this case the use of piezosurgery device represent a great advantage to reduce the invasivity and to preserve the alveolar nerve, infact the patient after the surgery he didn't have paresthesia and also using a piezo insert it was possible to reduce also the bone osteotomy using a micrometric cut.

\section{Bibliography}

1. Srivastava P., et al. "Comparison of surgical outcome after imparted third molar surgery using piezotome and the conventional rotary handpiece". Contemporary Clinical Dentistry 9.2 (2018): S318-S324.

2. Jiang Q and Qiu Y "Piezoelectric versus conventional rotary techniques for impacted third molar extraction. A Meta-analysis of Randomized Controlled Trials". Medicine (Baltimore) 94.41 (2015): e1685.

3. Al-Moraissi EA. "Does the piezoelectric surgical technique produce fewer postoperative sequelae after lower third molar surgery than conventional rotary instruments? A systematic review and meta analysis". International Journal of Oral and Maxillofacial Surgery 45.3 (2016): 383-391.

4. Goyal M and Marya K. "Comparative evaluation of surgical outcome after removal of impacted mandibular third molars using a Piezotome or a conventional handpiece: a prospective study". British Journal of Oral and Maxillofacial Surgery 50.6 (2012): 556-561.
5. Benediktsdottir IS., et al. "Mandibular third molar removal risk indicators for extended operation time postoperative pain and complications". Oral Surgery, Oral Medicine, Oral Pathology, Oral Radiology, and Endodontology 97.4 (2004): 438-446.

6. Oikarinen K. "Postoperative pain after mandibular third molar surgery". Acta Odontologica Scandinavica 49.1 (1991): 7-13.

7. Rullo R., et al. "Piezoelectric device vs Conventional rotative instruments in impacted third molar surgery: Relationships between surgical difficulty and postoperative pain with histological evaluations". Journal of Cranio-Maxillofacial Surgery 41.2 (2013): e33-e38.

8. Mantovani E., et al. "A split-mouth randomized clinical trial to evaluate the performance of piezosurgery compared with traditional technique in lower wisdom tooth removal". Journal of Oral and Maxillofacial Surgery 72.10 (2014): 1890-1897.

9. Vercellotti T., et al. "The piezoelectric bony window osteotomy and sinus membrane elevation: introduction of a new technique for simplification of the sinus augmentation procedure". International Journal of Periodontics and Restorative Dentistry 21.6 (2001): 561-567.

10. Vercellotti T. "Technological characteristics clinical indications of piezoelectric bone surgery". Minerva Stomatologica 53.5 (2004): 207-214.

11. Di Alberti L., et al. "A comparative study of densitometry during osseointegration: piezoelectric surgery versus rotary protocols". Quintessence International 41.8 (2010): 639-644.

12. Beziat JL., et al. "Ultrasonic osteotomy as a new technique in craniomaxillofacial surgery". International Journal of Oral and Maxillofacial Surgery 36.6 (2007): 493-500.

\section{Assets from publication with us}

- Prompt Acknowledgement after receiving the article

- Thorough Double blinded peer review

- Rapid Publication

- Issue of Publication Certificate

- High visibility of your Published work

Website: www.actascientific.com/

Submit Article: www.actascientific.com/submission.php Email us: editor@actascientific.com

Contact us: +919182824667 